\title{
Semantic memory: Searching for attributes vs searching for names*
}

\author{
ELLEN H. GROBER $\dagger$ \\ Johns Hopkins University, Baltimore, Maryland 21218 \\ and \\ ELIZABETH F. LOFTUS \\ University of Washington, Seattle, Washington 98104
}

\begin{abstract}
The purpose of this experiment was to determine whether searching for a word that has a particular attribute (a fruit that is yellow) involves a different process than searching for a word whose name has a particular form (a fruit whose name begins with "p"). Ss saw category nouns paired with adjectives or letter restrictors presented on a series of blocked trials and a series of mixed trials. The Ss had to produce a word that fell in the space defined by the noun and the restricting adjective or letter. RT was fastest when trials were blocked and when a letter followed the presentation of the noun. This finding suggested the existence of two retrieval plans that can be executed when $S$ has knowledge of the forthcoming type of item.
\end{abstract}

Recent experiments on the retrieval of information from long-term memory (LTM) have required an $S$ to produce a word that satisfies various restrictions, such as a word that names a member of the category fruits and also begins with the letter " $p$ " or a word that names a member of the category fruits that has the color yellow (Freedman \& Loftus, 1971; Loftus \& Suppes, 1972; Loftus \& Grober, 1973). In the Freedman and Loftus study, category-adjective and category-letter pairs were randomly mixed together in a long sequence of presentations. Some results of interest are as follows: response latencies for both stimulus types were faster if a high-frequency response was possible and were faster if the category was presented first. Response latencies for both stimulus types were unaffected by a number of variables, including the length of the interval between the presentation of the category and restrictor. Because category-adjective and category-letter stimuli (hereafter referred to as adjective and letter stimuli, respectively) were similarly affected by several variables, one retrieval process was thought to be executed when either letters or adjectives were used to restrict the response. To retrieve the name of a fruit that is yellow, the first step is to enter the appropriate category-fruits-and the second step is to search the category for a member that is appropriate. Similarly, to retrieve the name of a fruit beginning with the letter " $p$," the category fruits is first entered and then it is searched for an appropriate instance. In other words, Freedman and Loftus proposed that searching for a fruit that has a particular attribute (it must be yellow) involves the same process as

\footnotetext{
*The authors are extremely grateful to Bert Green for his statistical advice and to Alfonso Caramazza for discussing the whole paper with us.

†Requests for reprints should be addressed to: Ellen Grober, Department of Psychology, Johns Hopkins University, Baltimore, Maryland 21218.
}

searching for a fruit whose name has a particular form (it must begin with "p").

Philosophers have long recognized the distinction between the name of an object (a word) and the defining attributes of that object (Carnap, 1956; Quine, 1960). Recently, psychologists have incorporated this distinction between words and objects (concepts) into models for LTM by specifying a "name" relationship between a concept and its name (Collins \& Quillian, 1972; Rumelhart, Lindsay, \& Norman, 1972; Anderson \& Bower, 1973). Moreover, concepts need not have names, and the same name may apply to more than one concept. If the defining attributes of concepts are truly distinct from their names, perhaps the search for an attribute involves a different process from the search for a name.

Several methods have been successful in revealing different processing strategies (Madsen \& Drucker, 1966; Aderman \& Smith, 1970; Bjork, 1972; Bower, 1972; Reitman, Malin, Bjork, \& Higman, 1973). Aderman and Smith manipulated S's expectancies through the blocking of experimental trials. The blocking of trials permits $S$ to generate an efficient processing strategy which he can tailor to the demands of the experimental condition. We felt that blocking might reveal different retrieval plans for processing category-letter and category-adjective pairs.

In order to determine the effect of expectancy on retrieval, Ss saw category nouns paired with adjective or letter restrictors presented in three different ways: (1) adjective (MA) and letter (ML) trials mixed such that one type of trial followed the other randomly; (2) blocked adjective (BA) trials; (3) blocked letter (BL) trials. On half of the trials a short interval occurred between the presentation of the noun and the restrictor; on the remaining trials the interval was long. Prior to 
each series of trials of a given type, the Ss were told whether they would see nouns with letters or with adjectives or both. On all trials, the Ss responded with a word that fell in the space defined by the noun and the restricting letter or adjective.

We felt that blocking would reveal different retrieval processes, since the number of stimulus alternatives in each condition differed as did the ease with which the alternatives could be specified. With BL trials, there are a fixed number of well-defined stimulus alternatives that $S$ can expect as the forthcoming restricting letter. The amount of uncertainty under these conditions is 4.7 bits of information which can be completely reduced by five dichotomous questions (Garner, 1962). The set of stimulus alternatives with BA trials is, however, quite different. It is ill-defined and innumerable; the amount of uncertainty cannot be specified and consequently cannot be easily reduced. When trials are mixed, the set of stimulus alternatives includes the alternatives from both $\mathrm{BL}$ and $\mathrm{BA}$ trials (that is, any letter or adjective is possible). Thus, this set is not well-specified either; a great deal of uncertainty exists as to the identity of the forthcoming restrictor. Given this reasoning and the fact that RT is known to decrease as the amount of uncertainty decreases (Garner, 1962), we may expect $\mathrm{RT}$ to be considerably faster with $\mathrm{BL}$ trials than with the other types of trials. If this expected effect obtains, we will have demonstrated that blocking has a differential effect on adjective and letter stimuli. In addition, it would strongly suggest the existence of two retrieval plans that can be executed when $\mathrm{S}$ has knowledge of the forthcoming type of item.

As noted earlier, the interval between presentation of the category and the restrictor has been shown not to be an effective variable under mixed conditions (Freedman \& Loftus, 1971). This variable was included in the present study to verify the earlier result and to determine its effect under blocked conditions.

\section{METHOD}

\section{Subjects}

The Ss were 20 graduate students from the New School for Social Research. Each $S$ took part in one experimental session that lasted about $1 \mathrm{~h}$.

\section{Materials}

Stimuli were printed on $5 \times 8$ in. index cards. Each set consisted of a noun category plus either a restricting letter or a restricting adjective (e.g., fruit-yellow; fruit-p). Fifty-four noun categories were used.

The 54 nouns were each paired with two restrictors resulting in 108 distinct pairs. The noun always appeared first and the restrictor second. The interval between the presentation of the noun and the presentation of the restrictor was either short $(.5 \mathrm{sec})$ or long $(2.5 \mathrm{sec})$. Thirty-six noun-adjective pairs were selected at random from each of the 54 possibilities and used on BA trials. Thirty-six noun-letter pairs were selected at random from each of the 54 possibilities and used on BL trials. The remaining 36 pairs were used when trials were mixed.

Every S received all three types of trials (BA, BL, and mixed), and the order of trial types was balanced as completely as possible across Ss. The order of presentation of the noun pairs within each type was randomized. On half of the trials, the short interval was used; on the remaining trials, the long interval was used. The assignment of interval length was randomly determined with the order of presentation.

\section{Procedure}

The Ss were told that this was an experiment in memory. They would be presented with three series of trials. Each series would consist of 36 nouns each followed by either an adjective or a letter. They were to respond with a word that fell in the space defined by the noun and the restricting letter or adjective. Before each series of trials of a given type, the Ss were told whether they would see nouns with letters or adjectives or both. They were given four examples before each series and were told to respond as quickly as possible but to avoid errors.

The Ss sat in front of a screen in which there was a window covered by half-silvered glass. The index card containing the stimulus was placed in a dark enclosure behind the mirror and was presented by illuminating the enclosure. A microphone was placed in front of $S$, and he responded by talking into it.

A trial consisted of the following: (a) a card with the item printed in large type was placed in the darkened enclosure behind the half-silvered mirror; (b) the E said "ready" and pressed a button which illuminated the noun; (c) after a long or short interval, the restrictor was automatically illuminated and simultaneously an electric timer with a dc clutch was started; (d) the S's verbal response activated a voice key that stopped the clock and terminated the trial.

\section{RESULTS}

Only correct responses $(96 \%)$ were included in the following analyses. Most of the errors that occurred were due to a failure of the voice key to stop the clock. Data from the mixed trials were separated into "adjective" trials and "letter" trials for the analyses; thus the analyses considered the experiment to be a 2 by 2 by 2 completely crossed factorial (letter or adjective restrictor, mixed or blocked trials, short or long response delay) with Ss as the fourth factor, making a completely "within" design. Median latencies were obtained for each S's responses in each of the eight conditions. For each condition, group mean latencies across Ss were obtained, and these are shown in Table 1 . An analysis of variance using a repeated measures design with $\mathrm{Ss}$, interval duration, restrictor type, and condition as factors was done on the latency data. Responses to letter restrictors were significantly faster than to adjective restrictors $[F(1,19)=14.42, p<.005]$, and responses on blocked trials were slightly faster than on mixed trials, although the difference was not significant $[F(1,19)=3.69, .10<p<.05]$. The main effect of interval duration was not significant. The interaction that was critical to our argument was that of Trial Type by Restrictor Type; it was significant $[F(1,19)=6.58$, $\mathrm{p}<.025]$. Blocking did not effect the mean latency for adjective restrictors, but decreased considerably the mean latency for letter restrictors. There were no other significant interactions.

Inspection of the data in Table 1 suggests that the similarity among the mean latencies in the mixed conditions could mask the pattern of results in the 
Table 1

Group Mean Latency and Standard Error (in Seconds) for Each Condition

\begin{tabular}{|c|c|c|c|c|c|c|c|c|}
\hline \multirow{3}{*}{$\begin{array}{l}\text { Stimulus } \\
\text { Type }\end{array}$} & \multicolumn{4}{|c|}{ Mixed } & \multicolumn{4}{|c|}{ Blocked } \\
\hline & \multicolumn{2}{|c|}{ Short } & \multicolumn{2}{|c|}{ Long } & \multicolumn{2}{|c|}{ Short } & \multicolumn{2}{|c|}{ Long } \\
\hline & Mean & $\mathrm{SE}$ & Mean & SE & Mean & $\mathrm{SE}$ & Mean & SE \\
\hline Adjective & 1.65 & .09 & 1.70 & .07 & 1.69 & .08 & 1.73 & .11 \\
\hline Letter & 1.63 & .13 & 1.64 & .17 & 1.45 & .10 & 1.27 & .04 \\
\hline
\end{tabular}

blocked conditions. Accordingly, two separate analyses of variances were done on the latency data using a repeated measures design with Ss, interval duration, and restrictor type as factors. No significant effects were found in the mixed conditions. In the blocked conditions, responses to letter restrictors were significantly faster than to adjective restrictors $[F(1,19)$ $=16.22, p<.001]$. There was no significant effect of interval duration. The interaction of Restrictor Type by Interval approached significance $[\mathrm{F}(1,19)=3.18$, $.10<p<.05]$. The longer interval did not effect the mean latency for adjective restrictors, but decreased the mean latency for letter restrictors.

\section{DISCUSSION}

The major concern of this study was to determine whether the distinction that philosophers maintain between words and attributes has any psychological reality in the retrieval of information from LTM. The fact that RT is differentially affected by expectancy when letters vs adjectives are used as restrictors suggests to us the existence of two retrieval plans that can be executed when the $\mathrm{S}$ has knowledge of the forthcoming item.

The retrieval of information from LTM presumes a systematic organization of information, an extensive network of strategies, and a system of control processes that manipulate these resources in response to the requirements of each new experimental condition (Bower, 1967; Atkinson \& Shiffrin, 1968; Reitman, 1970). In order to manipulate these resources, $S$ must have some expectation of the characteristics of the task. The blocking of trials in this experiment permits $S$ to develop an efficient strategy to guide his performance.

The significant difference in RT when letters as opposed to adjectives are used as restrictors reflects a difference in the set of operations that controls S's performance. One possibility for why the fastest RTs occurred on BL trials is that S's expectation of a letter cue enabled him to execute a highly structured plan for searching memory after the noun category was presented, while the expectation of an adjective cue on BA trials does not permit a well-defined plan to be executed until after the adjective is actually presented.

The results of this experiment are consistent with predictions that can be made from the model proposed by Collins and Quillian (1972). This model is one of several network models that provide a framework for representing and processing information in LTM (Rumelhart, Lindsay, \& Norman, 1972; Kintsch, 1972; Anderson \& Bower, 1973). Information in the system is represented by a network of interrelated lists or concepts; radiating from each concept are paths to related properties. Going from one concept to another consists of activating a pathway between them; finding the intersection of two concepts consists of activating all the paths radiating from each of the concepts until a concept common to both is found.

From this model we have extrapolated a possible network for the concept of FRUIT which is illustrated in Fig. 1. It has pointers to the concepts of APPLE, PEAR, and BANANA via a subset relation and to the concepts of YELLOW and RED via a color relation. BANANA has a pointer to YELLOW and APPLE has a pointer to RED. Each of these concepts has a path defined by a name relation that connects it to its label.

When the $S$ is presented with the word fruit on BA trials, the path connecting the word fruit with the concept FRUIT is activated. The S may wait until the presentation of the adjective before executing the following set of operations: activate the path from the word yellow to its concept; find an intersection of the concepts of FRUIT and YELLOW such as the concept of BANANA; and activate the path connecting BANANA with its label to produce the response. The RT on MA trials $(1.67 \mathrm{sec})$ was not significantly different from the RT obtained for BA trials $(1.71 \mathrm{sec})$, possibly indicating that on MA trials the $S$ used a strategy similar to the one proposed for the BA trials.

When the $S$ is presented with the word fruit on $\mathrm{BL}$ trials, the path connecting the word fruit with its concept is activated. In the interval before the presentation of the letter, the $S$ may retrieve several appropriate concepts such as APPLE, PEAR, and BANANA and begin to trace back paths to their corresponding labels, storing these labels in STM. When

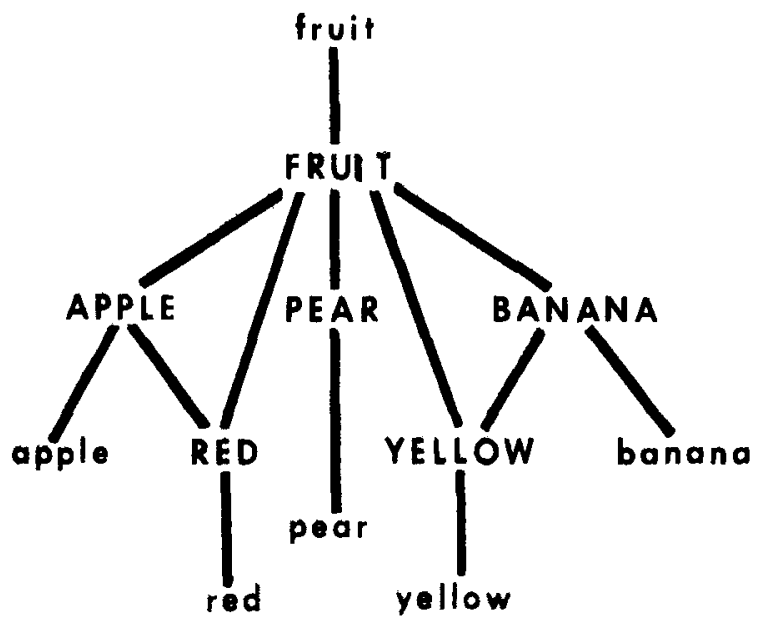

Fig. 1. Semantic network for the concept of FRUIT. 
the restricting letter " $p$ " appears, the S need only match that letter with the first letter of an appropriate label such as pear which he has stored in STM. On ML trials, the execution of a similar sequence of operations may not begin until after the presentation of the letter, resulting in longer RTs than on BL trials.

The fact that the fastest RTs were found with $\mathrm{BL}$ trials is consistent with the finding that the initial letters of stimulus items are powerful cues for the retrieval and subjective organization of words in memory (Tulving, 1962; Earhard, 1967). When the $S$ traces back the paths of retrieved concepts to their corresponding labels, he stores these words in STM and primes the first letter of each word to facilitate a match with the letter to be presented. In the interval between the presentation of the noun and the restricting letter, the $S$ is tracing back paths to labels of concepts, storing them in STM, and priming the first letter of each label. The longer the interval, the greater the number of paths that have been activated and the more likely it is that the $\mathrm{S}$ has stored in STM a word that will be an appropriate response to the letter presented.

\section{REFERENCES}

Aderman, D., \& Smith, E. E. Expectancy as a determinant of function units in pexceptual recognition. Cognitive Psychology, 1970, 2, 117-129.

Anderson, J., \& Bower, G. H. Human associative memory. Washington, D.C: Winston, 1973.

Atkinson, R. C., \& Shiffrin, R. M. Human memory: A proposed system and its control processes. In $K$. W. Spence and J. T. Spence (Eds.), Advances in the psychology of learning and motivation research and theory. Vol. 2. New York: Academic Press, 1968.

Bjork, R. A. Theoretical implications of directed forgetting. In A. Melton and E. Martin (Eds.), Coding processes in human memory. Washington, D.C: Winston, 1972.
Bower, G. H. A multicomponent theory of the memory trace. In K. W. Spence and J. T. Spence (Eds.), The psychology of learning and motivation. Vol. 1. New York: Academic Press, 1967.

Bower, G. H. Mental imagery and associative learning. in L. Gregg (Ed.), Cognition in learning and memory. New York: Wiley, 1972 .

Carnap, R. Meaning and necessity. Chicago: University of Chicago Press, 1056.

Collins, A. M., \& Quillian, M. R. How to make a language user In E. Tulving and W. Donaldson (Eds.), Organization of memory. New York: A cademic Press, 1972.

Earhard, M. The facilitation of memorization by alphabetic instructions. Canadian Journal of Psychology, 1967, 21, 15-23.

Freedman, J. L., \& Loftus, E. F. Retrieval of words from long-term memory. Journal of Verbal Learning \& Verbal Behavior, 1971, 10, 107-115.

Garnex, W. R. Uncertainty and structure as psychological concepts. New York: Wiley, 1962.

Kintsch. W. Notes on the structure of semantic memory. In E. Tulving and $W$. Donaldson (Eds.), Organization of memory. New York: Academic Press, 1972.

Loftus, E. F., \& Grober, E. H. Retrieval from semantic memory by young children. Developmental Psychology, 1973, 8, 310

Loftus, E. F. \& Suppes, P. Structural variables that determine the speed of retrieving words from long-term memory. Journal of Verbal Learning \& Verbal Behavior, 1972, 11, 770-777.

Madsen, M. C., \& Drucker, J. M. Immediate memory by missing scan and modified digit span. Psychonomic Science, 1966, 6 . 283-284.

Quine, W. Word and object. New York: Wiley, 1960.

Reitman, W. What does it take to remember? In D. Norman (Ed.), Models of human memory. New York: Academic Press, 1970 .

Reitman, W., Malin, J. T., Bjork, R. A., \& Higman, B. Strategy control and directed forgetting. Journal of Verbal Learning \& Verbal Behavior, 1973, 12, 140-149.

Rumelhart, D. E. Lind say, P. H., \& Norman, D. A. A process model for long-term memory. In E. Tulving and W. Donald son (Ed.), Organization of memory. New York: Academic Press, 1972 .

Tulving, E. The effect of alphabetical subjective organization on memorizing unrelated words. Canadian Journal of Psychology, $1962,16,185-191$.

(Received for publication June 21, 1973; revision received October $21,1973$. ) 